\title{
ФОРМИРОВАНИЕ НАУЧНО-ОБРАЗОВАТЕЛЬНОГО ТУРИСТСКОГО КЛАСТЕРА НА БАЗЕ МУЗЕЕВ САНКТ-ПЕТЕРБУРГСКОГО ГОРНОГО УНИВЕРСИТЕТА (РОССИЯ) И ФРАЙБЕРГСКОЙ ГОРНОЙ АКАДЕМИИ (ГЕРМАНИЯ)
}

\author{
Г.А.КАРПОВА ${ }^{1}$, В.А.ТКАЧЕВ ${ }^{1}$, Г.ХАЙДЕ ${ }^{2}$, И.В.ТАЛОВИНА ${ }^{3}$ \\ ${ }_{1}^{1}$ Санкт-Петербургский государственный экономический университет, Санкт-Петербург, Россия \\ ${ }^{2}$ Институт минералогии Фрайбергской горной академии, Фрайберг, Германия \\ ${ }^{3}$ Санкт-Петербургский горный университет, Санкт-Петербург, Россия
}

\begin{abstract}
Университетские музеи представляют собой группу специализированных учебных музеев различного профиля, которые создаются для повышения эффективности учебного процесса, являются базой для научных исследований преподавателей и учащихся и способствуют развитию, трансферу и популяризации знаний. Формирование научно-образовательного туристского кластера на базе двух старейших горных музеев и вузов мира позволит создать современную многофункциональную структуру с высокой степенью междисциплинарности, что даст возможность развить новые формы кластерного взаимодействия, которые будут включать в себя элементы различных отраслей и сфер знания и гарантировать не только экономические преимущества, но и выполнять важную социальную роль в развитии общественных отношений. Ядром кластерной структуры нового типа могут служить образовательные организации, учреждения сферы культуры, научно-исследовательский сектор, специализированные организации сферы физической культуры и спорта, предприятия и организации индустрии развлечения. Отдельного внимания заслуживают варианты комбинации перечисленных сфер для популяризации знаний в новом, современном формате, в частности, посредством формирования научно-образовательного туристского кластера на основе университетских музеев.

Ключевые слова: научно-образовательный туристский кластер; Горный музей Санкт-Петербургского горного университета; Горный музей Фрайбергской горной академии; многофункциональные структуры; междисциплинарная специализация; формы кластерного взаимодействия
\end{abstract}

Как цитировать эту статью: Формирование научно-образовательного туристского кластера на базе музеев Санкт-Петербургского горного университета (Россия) и Фрайбергской горной академии (Германия) / Г.А.Карпова, В.А.Ткачев, Г.Хайде, И.В.Таловина // Записки Горного института. 2018. Т. 232. С. 341-346. DOI: 10.31897/PMI.2018.4.341

Актуальность и постановка проблемы. Кластерные структуры в современных условиях являются неотъемлемой частью практически любой страны, независимо от осуществляемой государственной политики и уровня благосостояния общества. Вместе с тем, кластеры как феномен социально-экономического и инновационного развития возникли относительно недавно лишь начиная с середины XX века можно говорить о процессе кластеризации, обеспечивающем устойчивый рост в отраслевом или региональном контексте. В последние годы кластерные технологии коснулись социальной сферы и, в первую очередь, ее научно-образовательной составляющей.

В историческом аспекте активное появление кластерных структур следует относить к 70-м годам прошлого века. Это был первый этап, начало которого было связано с необходимостью увеличения производительности труда и роста масштабов производства в промышленности. Деятельность по созданию и развитию такого рода кластеров преследовала не только экономические, но и сугубо политические цели, а конечным потребителем являлись все участники рынка государство, предприятия и домашние хозяйства в пропорциональной зависимости от объемов платежеспособного спроса. Ключевую роль в организации кластерных структур на первоначальном этапе осуществляло государство, однако, в дальнейшем, все большее количество промышленных кластеров будет связано с активностью частного бизнеса, заинтересованного в возможности значительного увеличения доходности коммерческой деятельности за счет общего снижения затрат и их оптимизации в долгосрочном периоде. Результатом кластерной деятельности становится готовая продукция, масштабы производства и уровень качества которой значительно выше аналогов, полученных в рамках традиционного производства. Кластерные структуры в промышленности отличаются высоким уровнем инноваций, наличием тесной взаимосвязи с научно-исследовательскими центрами, которые весьма часто являются составным элементом подобного рода производственных комплексов, а также высоким уровнем кооперации с наличием вертикальных и горизонтальных взаимосвязей между участниками - предприятиями, входящими 
в тот или иной кластер. Среди отраслей народного хозяйства, где уже длительный период времени успешно используются кластерные структуры, можно выделить горно-рудную промышленность, автомобилестроение, фармацевтическую отрасль, химическую промышленность и ряд других.

Второй этап кластерного развития, пик которого пришелся на 90-е годы прошлого века, тесно связан с применением кластерных инициатив в сфере услуг. Данное обстоятельство обусловлено повышением значимости сферы услуг для обеспечения стабильного экономического роста и высокой степени международной интеграции стран с опережающими темпами развития. Вместе с тем, такого рода кластеры, по сравнению с промышленными, обладают целым рядом отличительных особенностей. В качестве характерного примера можно рассмотреть кластеры в сфере рекреации и туризма, практика по созданию и развитию которых широко распространена как в зарубежных странах, так и в современных российских условиях. Роль государства по формированию и развитию туристских кластеров заключается в обеспечении возможности реализации системы государственно-частного партнерства при осуществлении крупных кластерных инициатив. Пространственное размещение такого рода кластеров будет находиться в непосредственной взаимосвязи от туристско-рекреационного потенциала территории, а также учитывать возможности развития перспективных видов туризма в рамках определенной туристской дестинации. Вместе с тем, такого рода кластер обладает, по сравнению с промышленными, средним уровнем внедрения инноваций, достаточно низкой взаимосвязью с научно-исследовательским сектором и относительно высоким уровнем специализации. Наибольшее распространение в повседневной практике получили туристские кластеры санаторно-курортной направленности, объединяющие рекреационные комплексы и элементы туристской инфраструктуры, а также кластеры, связанные с реализацией проектов в сфере спорта и экстремальных развлечений.

Современный этап кластерного строительства ориентирован на создание многофункциональных структур, которые отличались бы более высокой междисциплинарной специализацией, чем все перечисленные варианты. Новые формы кластерного взаимодействия должны включать в себя элементы различных отраслей и сфер знания, что должно способствовать достижению значительного синергетического эффекта и гарантировать не только экономические преимущества, но и выполнять важную социальную роль в развитии общественных отношений. Ядром кластерной структуры нового типа могут служить образовательные организации, учреждения сферы культуры, научно-исследовательский сектор, специализированные организации сферы физической культуры и спорта, предприятия и организации индустрии развлечения. Отдельного внимания заслуживают варианты комбинации перечисленных сфер в рамках одной организационно-правовой формы. В качестве примера авторы обращаются к деятельности университетских музеев, которые следует рассматривать в качестве потенциальной основы для реализации будущих кластерных инициатив по созданию научно-образовательных туристских кластеров [7-12].

Целью создания научно-образовательных туристских кластеров на базе университетских музеев следует считать планомерную многофункциональную деятельность по повышению образовательного и научного уровня различных категорий потребителей, формированию общекультурных и профессиональных компетенций и навыков, сохранению и пополнению музейных фондов при одновременном увеличении востребованности объектов экскурсионного показа как инфраструктурного элемента туристской дестинации $[2,3,5]$.

Задачи, решаемые в процессе создания и реализации научно-образовательного туристского кластера на базе университетских музеев, можно систематизировать в рамках пяти основных направлений:

- образовательная деятельность - обеспечение тесной взаимосвязи между учебным процессом отдельных категорий потребителей услуг и функциональными возможностями университетских музеев $[4,6]$;

- научно-исследовательская деятельность - проведение научных, в том числе междисциплинарных, исследований и изысканий с использованием музейного фонда в рамках различных отраслей знаний;

- музейная деятельность - сохранение и пополнение музейного фонда, обновление материально-технической базы выставочного оборудования, совершенствование условий демонстрации музейных экспонатов, проектирование интерактивного пространства в рамках существующего музейного комплекса, разработка новых форм и направлений экскурсионного показа; 
- нравственно-воспитательная деятельность - повышение нравственного уровня различных слоев населения, сохранение фундаментальных ценностей общества, развитие экологических инициатив в условиях постиндустриального общества и «зеленой экономики»;

- туристская деятельность - повышение туристской аттрактивности университетских музеев как элемента инфраструктуры дестинации за счет развития системы организованного туризма.

В качестве ядра одного их проектируемых научно-образовательных туристских кластеров можно рассматривать Горный музей Санкт-Петербургского горного университета и музеи Фрайбергской горной академии, обладающие уникальными минералогическими коллекциями. Рассмотрим эти академические центры с точки зрения потенциала для организации и участия в развитии кластерной структуры.

Университетские музеи как основа для реализации кластерных инициатив по созданию научно-образовательных туристских кластеров. Университетские музеи представляют собой группу специализированных учебных музеев различного профиля, которые создаются для повышения эффективности учебного процесса, являются базой для научных исследований преподавателей и учащихся и способствуют развитию, трансферу и популяризации знаний. Первые музеи начали появляться в конце XVIII - начале XIX веков, когда в университетах начали формироваться кабинеты редкостей, мюнц-кабинеты, собрания приборов и моделей, необходимые для ведения образовательного процесса, его наглядности. Создавались они в соответствии с университетскими уставами, а также по инициативе частных лиц, ученых, меценатов, в результате выставочной деятельности и развивались в процессе развития отечественной науки и системы образования.

На протяжении XIX-XX веков университетские музеи служили центрами научной мысли и образования, отражали текущее состояние развития минерально-сырьевой базы и технологий. Вокруг таких музеев концентрировались все великие ученые и изобретатели. В настоящее время наблюдается обратная тенденция резкого сокращения числа университетских музеев по всему миру, в том числе в таких развитых странах, как Германия. В 2017 г., например, закрыт знаменитый палеонтологический музей Лейпцигского университета, частично утеряны ботанические коллекции Ботанического сада Йенского университета и т.д. Связано это не столько с проблемами финансирования, сколько с падением публичного и научного интереса к музеям классического типа, лишенным, как правило, современных интерактивных средств подачи информации, визуальных спецэффектов, компьютерных технологий и т.д.

Горный музей Санкт-Петербургского горного университета. Горный музей СанктПетербургского горного университета основан одновременно с Горным училищем и утвержден его Уставом от 28 июня 1774 г. (рис.1). Начало музейному собранию положил Минеральный кабинет «Российских и иностранных минеральных ископаемых тел». В настоящее время Горный музей - хранитель уникальных коллекций минералов, горных пород и руд, палеонтологических остатков, собрание моделей и макетов по истории горной и горно-заводской техники, холодного оружия, изделий камнерезного и ювелирного искусства, которые составляют экспозиции 12 основных залов музея. Музей является учебно-научным и культурно-просветительным подразде-
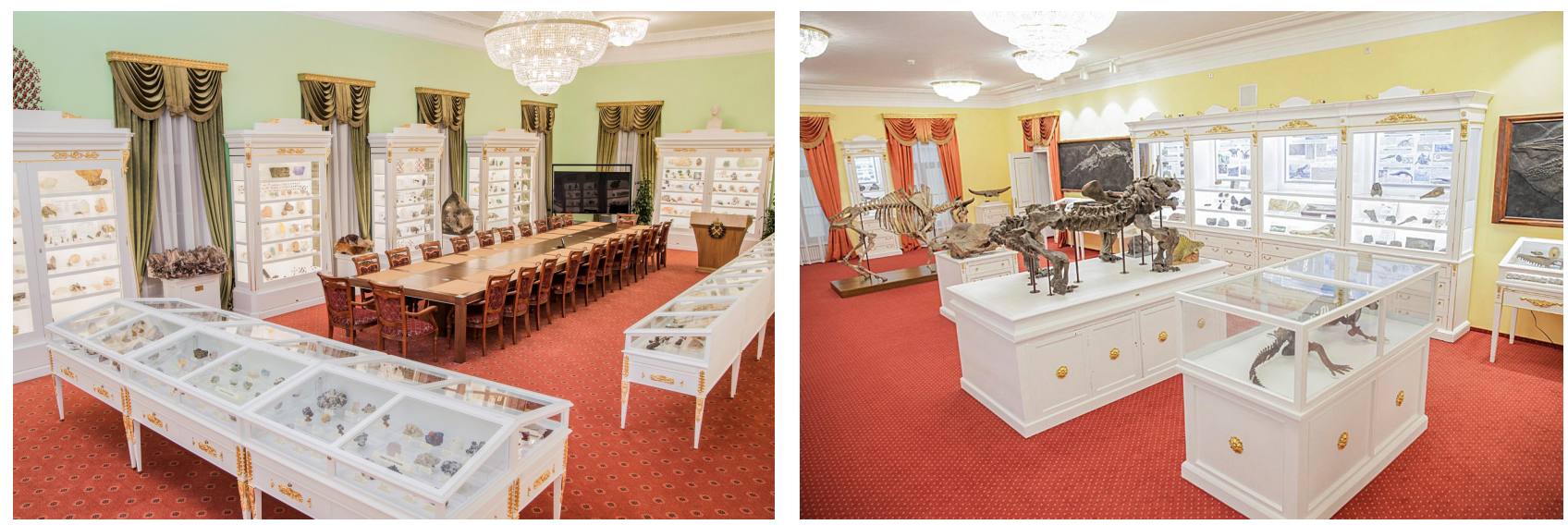

Рис.1. Залы Горного музея Санкт-Петербургского горного университета 
лением университета. В 2016 г. в музее проведены фундаментальный ремонт и реконструкция, важнейшей целью которых являлось создание лучших условий для реализации возможностей музейной деятельности по двум направлениям:

• научно-образовательной, служащей интересам высшего образования и развитию научных знаний в области наук о Земле;

- популяризаторской, направленной на распространение и популяризацию научных геологических знаний и формирование в обществе эстетического восприятия мира геологии и горного дела.

Оба направления предполагают тесную связь и взаимодействие музея с профильными кафедрами, учебным процессом и активное участие в подготовке высококвалифицированных специалистов горно-геологического профиля.

Горный музей и уникальная минералогическая выставка «Terra Mineralia» Фрайбергской горной академии. Не менее славная история и у Фрайбергской горной академии. В 1765 г. принц Франц Ксавер Саксонский основал школу профессионального обучения горняков под именем «Курфюршеская саксонская горная академия Фрайберга», которая очень быстро становится одним из самых значительных центров мировой науки и культуры. В Горной академии Фрайберга были открыты два химических элемента: индий (Фердинанд Райх, 1863) и германий (Клеменс Винклер, 1886). Уже в конце XVIII века здесь начинает формироваться едва ли не самое первое минералогическое собрание в мире. На протяжении последующих веков оно постоянно пополняется и в настоящее время насчитывает около 500000 экспонатов, представленных в пяти главных залах музея. Помимо университетского собрания, Академия является обладателем уникальной минералогической выставки «Terra Mineralia». В 2004 г. швейцарским благотворительным фондом Поль-Штреер (Pohl-Ströher) Техническому университету «Фрайбергская горная академия» в бессрочное владение была передана богатейшая минералогическая коллекция г-жи Эрики Поль-Штреер, которая легла в основу выставки. За 40 лет ею была собрана великолепная коллекция из 5 тысяч уникальных экспонатов. Таким образом, университет г. Фрайберга получил одну из самых крупных и ценных частных минералогических коллекций в мире, что позволило этому собранию стать одним из самых значимых минералогических музеев мира.

С научной точки зрения передача коллекции г-жи Эрики Поль-Штреер явилась для университета уникальным событием, поскольку в XX веке Академия по разным, в том числе политическим причинам, не имела возможности пополнять университетскую коллекцию, и выставка «Terra Mineralia» идеально дополнила уже существующие коллекции университета. Для достойного размещения коллекции Академия получила грант ЮНЕСКО на реконструкцию старинного замка саксонских герцогов - крепость Фройденштайн, расположенную в центре Фрайберга (рис.2). Минералогическая выставка «Terra Mineralia» была открыта в конце 2008 г.

Основная часть минералогической коллекции занимает второй и третий этажи замка. В отличие от Минералогического собрания Института минералогии Фрайбергской горной академии, где экспонаты расположены по классам химических соединений (как и в Горном музее Санкт-

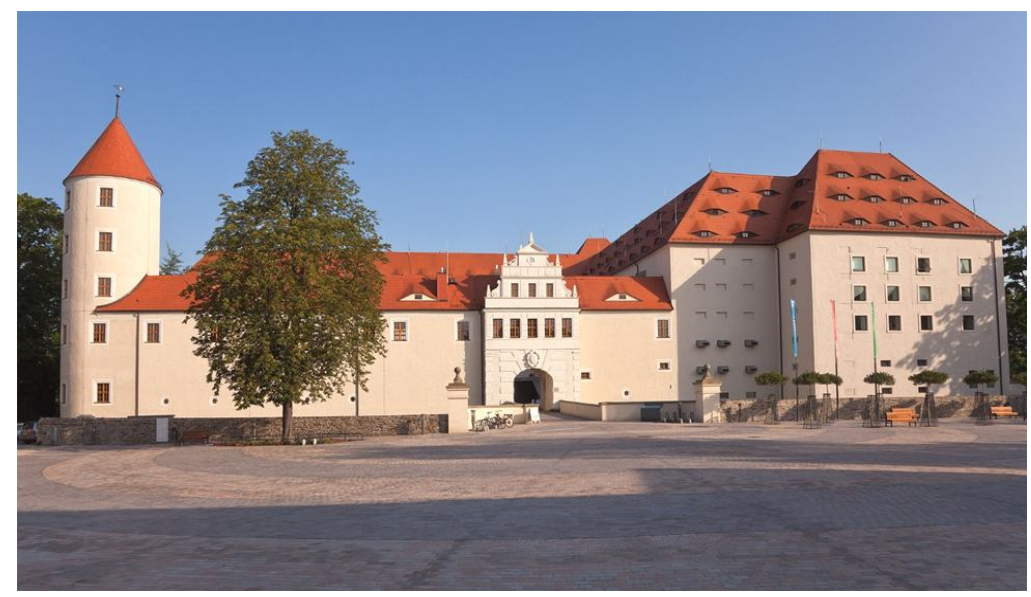

Рис.2. Крепость Фройденштайн старинный замок саксонских курфюрстов
Петербургского горного университета), систематика экспонатов «Terra Mineralia» выполнена по географическому принципу - в разных залах представлены коллекции образцов, собранные на территории Азии, Австралии, Америки, Африки и Европы. Выставка оборудована по последнему слову техники, ее концепция позволяет полностью погрузиться в мир минералов: полы, потолки и витрины, выполненные несколько аскетично в черном цвете, создают контраст с окрашенными в белый цвет историческими стенами; что- 
бы не нарушать очень профессионально выполненную подсветку минералов, на окнах установлены ставни, предотвращающие попадание прямого солнечного света, при этом помещение не испытывает недостатка в свете, он льется прямо из витрин, от самих минералов. Таким образом, все внимание посетителя обращено именно на экспонаты, что и является основной идеей выставки - показать красоту камня. В замке оборудован также небольшой научный центр, доступный для всех посетителей выставки и студентов Академии. На первом этаже находится сокровищница

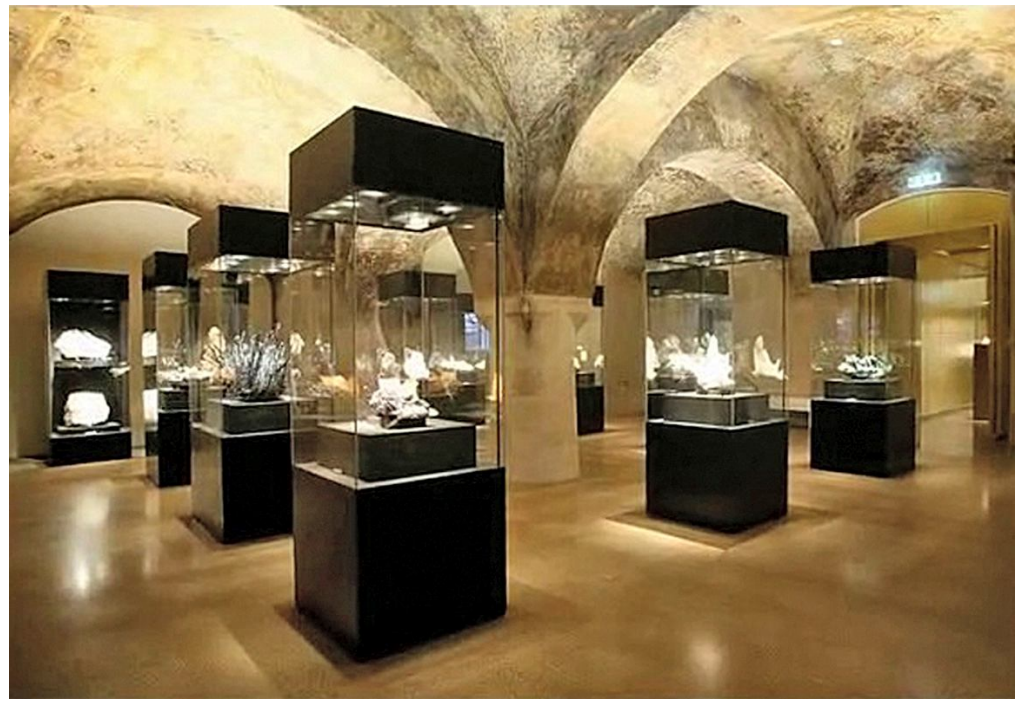

Рис.3. Минералогическая выставка «Terra Mineralia» (рис.3), где собраны наиболее выдающиеся экспонаты коллекции (драгоценные камни, метеориты и т.д.). В подвальных помещениях замка оборудованы запасники и фонды музея, оснащенные по последнему слову техники и музейного искусства.

Таким образом, выставка ориентирована не только на научное, но и на эстетическое восприятие камня, его красоту и многообразие. Для привлечения юного поколения к изучению минералогии и геологии выставка содержит и некоторые элементы игровой и интерактивной подачи материала - на простых моделях можно представить строение кристаллической решетки изнутри, увидеть принцип возникновения пъезоэффекта, заглянуть в поляризационный микроскоп, узнать какое применение рудные минералы находят в науке и технике. В целом, с самых разных точек зрения выставка является идеальным примером современного минералогического музейного объекта.

Формирование научно-образовательного туристского кластера на базе горных музеев. Формирование научно-образовательного туристского кластера на базе музеев Горного университета Санкт-Петербурга и Фрайбергской горной академии основано на успешном многолетнем и многовековом сотрудничестве двух старейших технических вузов в образовательной, научной и культурной сфере. Совместная деятельность музеев в рамках проектируемого кластера будет опираться на заявленные ключевые задачи и предполагает поэтапную реализацию целого ряда управленческих решений:

- формирование стратегии развития научно-образовательного туристского кластера на базе университетских музеев;

- разработка организационной структуры и определение центров ответственности в процессе создания научно-образовательного туристского кластера на базе университетских музеев;

- характеристика объемов и структуры источников финансирования деятельности проектируемого кластера;

- проведение сегментации групп потребителей услуг, их социально-экономическая характеристика;

- разработка ежегодного плана мероприятий и событийного календаря научнообразовательного туристского кластера на базе университетских музеев;

- определение и реализация мероприятий по повышению имиджа и узнаваемости проектируемого кластера;

- осуществление функциональной взаимосвязи между учебными планами различных уровней и направлений подготовки и деятельностью научно-образовательного туристского кластера на базе университетских музеев;

- адаптация региональных туристских маршрутов с целью включения музейного комплекса проектируемого кластера в обязательные объекты туристского показа; 
- проектирование интерактивного пространства научно-образовательного туристского кластера на базе университетских музеев;

- разработка проектов сувенирной продукции научно-образовательного туристского кластера на базе университетских музеев (для определения и реализации мероприятий по повышению имиджа и узнаваемости горных музеев).

Заключение. Формирование научно-образовательного туристского кластера на базе двух старейших горных музеев и вузов мира позволит создать современную многофункциональную структуру с высокой степенью междисциплинарной специализации, что даст возможность развить новые формы кластерного взаимодействия, которые будут включать в себя элементы различных отраслей и сфер знания и гарантировать не только экономические преимущества, но и выполнять важную социальную роль в развитии общественных отношений.

\section{ЛИТЕРАТУРА}

1. Бизнес и патриотизм: проблемы совместимости / А.В.Завражин, А.М.Герасимов, Ю.А.Давыдова и др. М.: Изд-во МЭСИ, 2014. 214 с.

2. Гришин С.Ю. Формирование интегрированной системы управления туристской деятельностью в современных условиях // Теория и практика сервиса: экономика, социальная сфера технологии. 2014. № 1 (19). С. 131-140.

3. Гришин С.Ю. Туристско-рекреационное проектирование / С.Ю.Гришин, А.С.Баранов, О.Н.Крюкова. СПб: Изд-во СПбГЭУ. 2014. 148 с.

4. Казанин О.И. Горное образование в ХХІ веке: глобальные вызовы и перспективы / О.И.Казанин, К.Дребенштедт // Записки Горного института. 2017. Т. 225. С. 369-375.

5. Карпова Г.А. Развитие туризма как конкурентное преимущество территории (на примере субъектов СЗФО) / Г.А.Карпова, Е.О.Валеева // Известия Санкт-Петербургского государственного экономического университета. 2015. № 1 (91). C. 44-51.

6. Катунцов Е.В. Применение средств электронного обучения при подготовке специалистов в области информационных технологий для предприятий минерально-сырьевого комплекса / Е.В.Катунцов, Я.Култан, А.Б.Маховиков // Записки Горного института. 2017. Т. 226. С. 503-508.

7. Кружалин В.И. Состояние российского туризма, проблемы и перспективы / В.И.Кружалин, К.В.Кружалин, Н.В.Шабалина // Вестник Национальной академии туризма. 2016. № 1. С. 10-13.

8. Управление туристскими дестинациями на принципах кластеризации / Г.А.Карпова, С.Ю.Гришин, Е.В.Песоцкая, В.А.Ткачев. СПб: Изд-во СПбГЭУ. 2017. 153 с.

9. Hirshchman A.O. A Propensity to Self-subversion / Harvard College. Cambridge, 1995. $430 \mathrm{p}$.

10. Porter M.E. Clusters and the New Economics of competition // Harvard Business Review. 1998. № 76(6). P. 77-90.

11. Rosenfeld S.A. Bringing Business Clusters into the Mainstream of Economic Development // European Planning Studies. 1997. № 1, 5. P. 3-23.

12. Solvell $O$. The Cluster Initiative Greenbook CIND, Uppsala University, ISC, Harvard Business School. TSI Global Conference. Gothenburg, 2012. $391 \mathrm{p}$.

Авторы: Г.А.Карпова, д-р экон. наук, профессор, karpovaga@rambler.ru (Санкт-Петербургский государственный экономический университет, Санкт-Петербург, Россия), В.А.Ткачев, канд. экон. наук, дочент, quebrador@yandex.ru (Санкт-Петербургский государственный экономический университет, Санкт-Петербург, Россия), Г.Хайде, д-р, профессор, gerhard.heide@tu-freiberg.de (Институт минералогии Фрайбергской горной академии, Фрайберг, Германия), И.В.Таловина, д-р геол.-минерал. наук, профессор, talovina_iv@pers.spmi.ru (Санкт-Петербургский горный университет, Санкт-Петербург, Россия).

Статья поступила в редакиию 12.04.2018.

Статья принята к публикачии 9.07.2018. 